\title{
Carcinoma of the thyroid in myxoedema
}

\author{
G. SCLARE AND A. NICOL \\ From the Departments of Pathology, Crumpsall Hospital, Manchester \\ and University of Manchester
}

SYNOPSIS Three cases of carcinoma of the thyroid have been found in a post-mortem study of 37 cases of myxoedema. Each example of invasive carcinoma was accompanied by more widespread epithelial abnormalities which, though histologically similar, were not themselves demonstrably malignant.

It is probable that in myxoedema, as in chronic thyroiditis, excessive secretion of thyrotropic hormone leads to an increased susceptibility to carcinoma of the thyroid.

Carcinoma of the thyroid, though occasionally reported in cases of chronic thyroiditis, is not usually accepted as a complicating feature of myxoedema. In a previous post-mortem study of the thyroid (Sclare, 1963), one example of carcinoma was found among 25 cases of myxoedema. Since then, two examples of carcinoma have been found among a further 12 cases of myxoedema. In three patients, the onset of myxoedema had followed treatment of a preceding thyroid disorder; none of these developed thyroid carcinoma. The remaining 34 patients had all been diagnosed clinically as 'spontaneous' classical myxoedema, i.e., nongoitrous hypothyroidism, and in none had there been any clinical suspicion of carcinoma. Cases of hypothyroidism secondary to pituitary disease have not been included.

\section{CASE REPORTS}

CASE 1 (CASE 22 OF THE PREVIOUS SERIES) A woman aged 64 years with myxoedema, diagnosed 18 months before death, had been treated throughout that time with doses of thyroid extract ranging from $\frac{1}{2}$ gr. to 2 gr. daily. This patient had also suffered from myasthenia gravis for 12 years and multiple sclerosis for 15 months. Death was due to acute pancreatitis following cholecystectomy for gall-stones. The thyroid weighed $14.5 \mathrm{~g}$., was symmetrical, and of normal appearance externally. The cut surface of both lobes was composed of fibrous tissue with a scattering of pink and pale grey nodules, varying in size up to $5 \mathrm{~mm}$. in diameter.

Microscopically there are multiple small nodules in a mass of fibrous tissue throughout which there are small ragged acini and groups of oxyphilic cells, as well as focal and diffuse infiltration by lymphocytes and plasma cells. The nodules are of varying appearance, some

Received for publication 25 November 1963. differing little from normal thyroid tissue, others being composed of abnormally large acini distended by colloid. Among the nodules in the three sections examined $\overrightarrow{\mathscr{O}}$ initially there is one nodule which is enclosed by a thick capsule of hyaline connective tissue; the epithelium in this nodule is arranged in papillary fashion (Fig. 1). There is undoubted invasion of the fibrous capsule but no spread to the neighbouring thyroid tissue.

Further sections examined subsequently show in general the same combination of multiple small nodules $\mathbb{Q}$ and diffuse fibrosis. In one nodule, however, the epi- $\overrightarrow{\vec{A}}$ thelium is of very disorderly arrangement (Fig. 2), $\frac{0}{3}$ though less certainly malignant than the nodule shown in Figure 1. In another section there is an area of frank invasive adenocarcinoma, unrelated to any nodule (Fig. 3).

CASE 2 A woman aged 70 years was obviously myxoedematous on her first admission to hospital seven $\delta$ weeks before death. The family doctor thought that this $₹$ diagnosis had at one time been made at another hospital, 은 but no reliable history was available. Her hypothyroid condition improved on treatment with L-thyroxine, beginning with $0.1 \mathrm{mg}$. and later increasing to $0.2 \mathrm{mg}$. daily. She was re-admitted to hospital in congestive cardiac $N$ N failure and died suddenly two days later. At necropsy there was severe generalized atheroma, both mitral and 0 aortic valves showed gross calcific stenosis, and there $\omega$ were numerous recent pulmonary infarcts. The thyroidO was small $(5.5 \mathrm{~g}$.), symmetrical, and was separated frome the surrounding tissues with little difficulty. The cut surface was uniformly pale, tough, and fibrous.

Microscopically the greater part of the gland is: replaced by dense fibrous tissue; islets of surviving parenchyma are small and sparse, and are heavily $\overrightarrow{\mathbb{D}}$

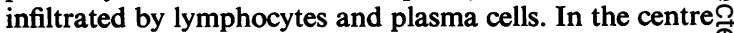
of the right lobe there is a carcinoma composed of $\mathbb{Q}$ compact masses of spheroidal cells separated by bandso of hyaline connective tissue (Fig. 4); several of the nuclei are of bizarre hyperchromatic type but there are noO 


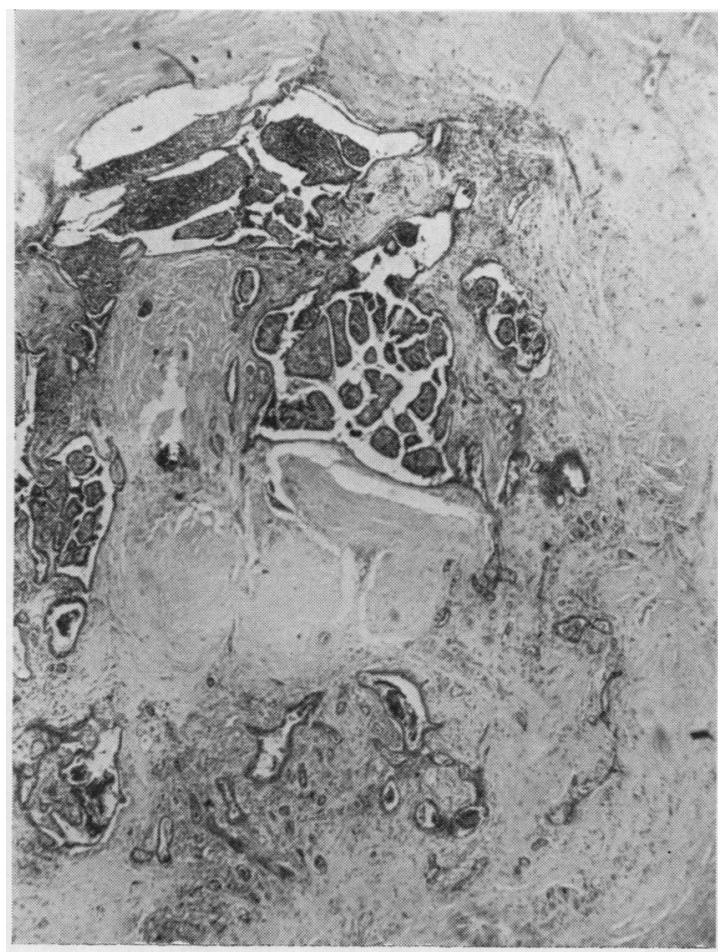

FIG. 1

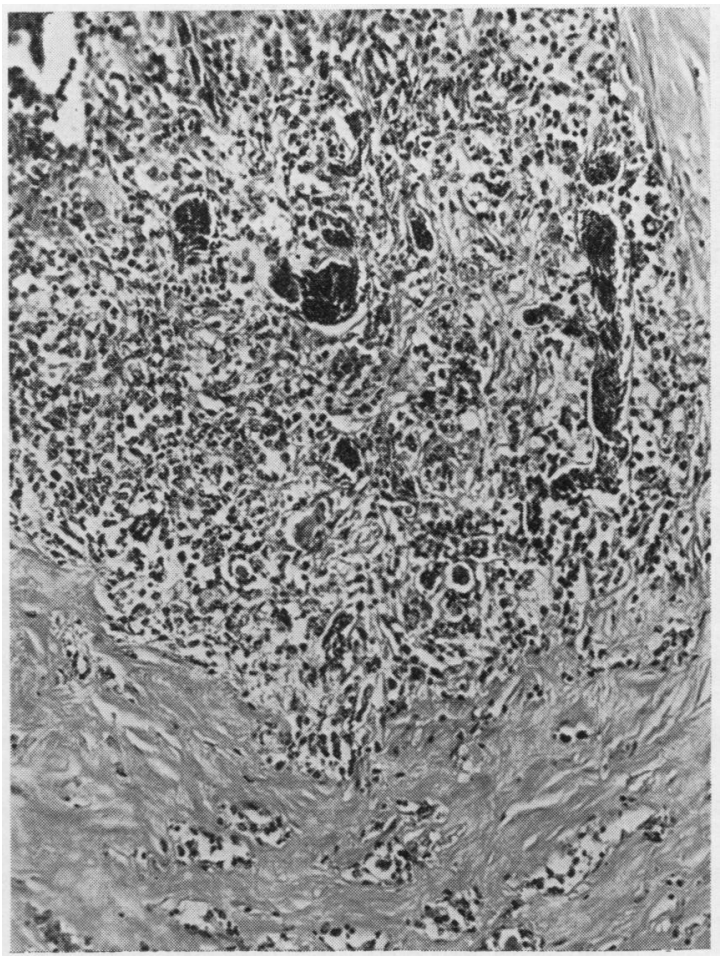

FIG. 2

FIG. 1. Case 1. Papillary adenocarcinoma infiltrating the capsule of the nodule. Haematoxylin and eosin $\times 30$.

FIG. 2. Case 1. A nodule in which there is epithelial disorder but no definite evidence of malignancy. Haematoxylin and eosin $\times 100$.

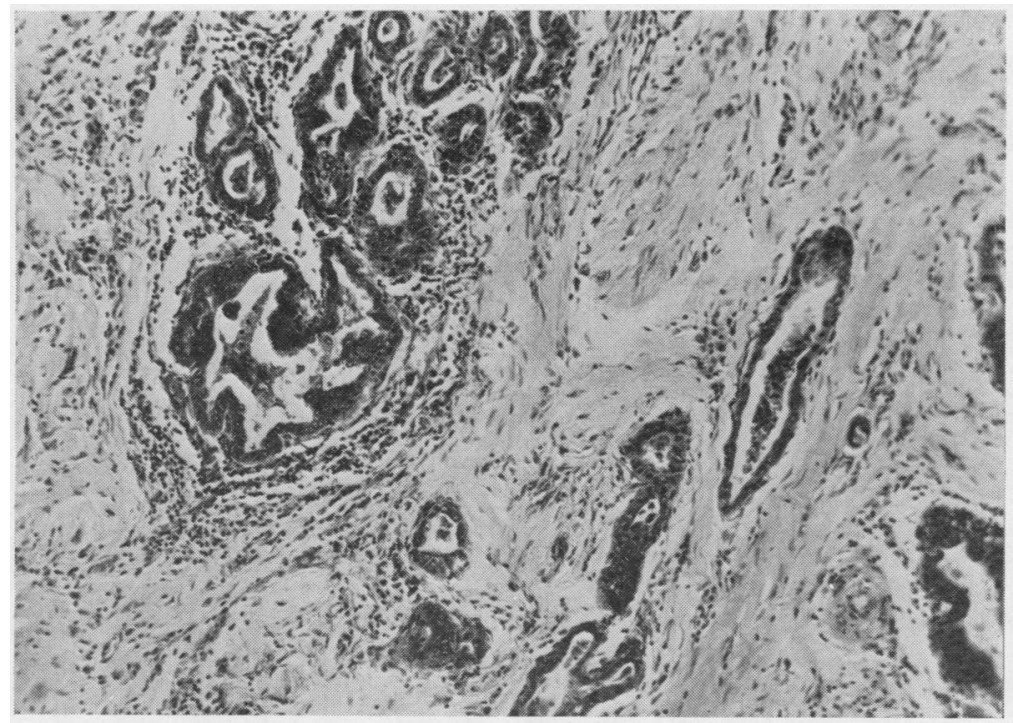

FIG. 3. Case 1. Invasive

adenocarcinoma, without obvious relation to the nodules.

Haematoxylin and eosin $\times 100$.

FIG. 3 


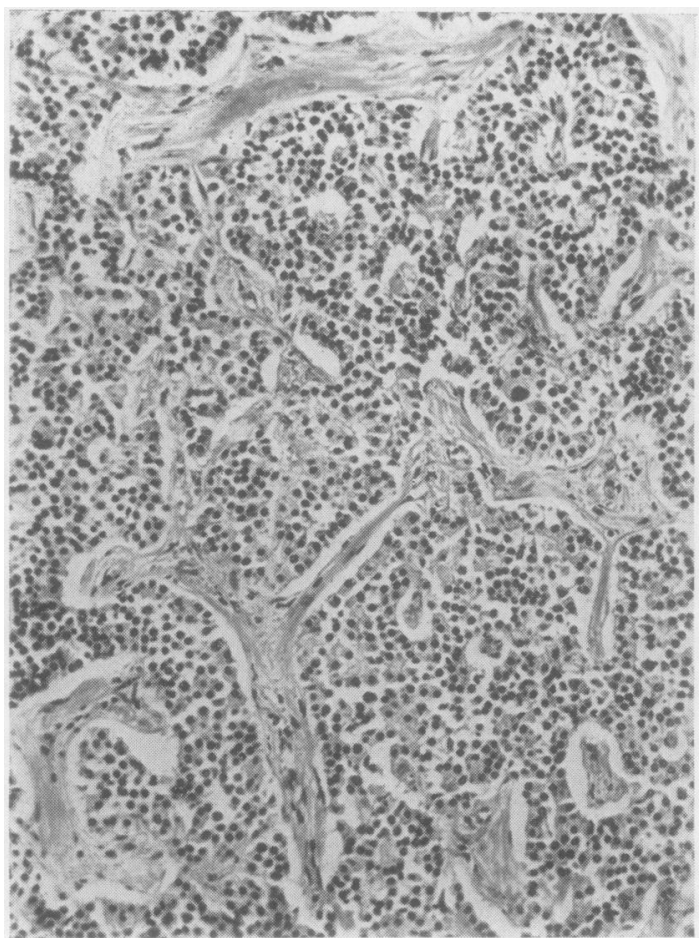

FIG. 4. Case 2. Spheroidal-cell carcinoma in the right lobe. Haematoxylin and eosin $\times 100$.

mitotic figures. Lymphatic invasion is seen at one margin. In the left lobe there are two adjacent foci of similar appearance (Fig. 5) but lacking evidence of stromal or lymphatic invasion. Confirmation of the malignant nature of the tumour is provided by the presence of a small group of similar cells in a cervical lymph node.

CASE 3 Myxoedema and diabetes mellitus were diagnosed during investigation of an intracranial tumour in a woman aged 65 years. Improvement followed treatment with thyroid extract, 1 gr. daily, later changed to L-thyroxine, $0.1 \mathrm{mg}$. and then $0.2 \mathrm{mg}$. daily. A meningioma, confirmed histologically, was removed from the right frontal region but the patient died seven weeks later. Necropsy showed old and recent myocardial infarction and bronchopneumonia. The thyroid weighed $19 \mathrm{~g}$. and was symmetrical and of normal appearance externally. Section showed many rounded pale grey foci, of 1 to $3 \mathrm{~mm}$. diameter, scattered profusely throughout both lobes. There was also a firm, pale grey mass, $10 \mathrm{~mm}$. in diameter, in the centre of the right lobe.

Microscopically the gland is traversed by narrow bands of fibrous tissue. Foci of lymphocytic infiltration, many in the form of lymphoid follicles, are large and numerous. The thyroid acini are of substantially normal appearance. The mass noted macroscopically in the right lobe is a papillary adenocarcinoma (Fig. 6), infiltrating the neighbouring stroma. Throughout the remainder of both lobes the inflammatory foci are accompanied by a

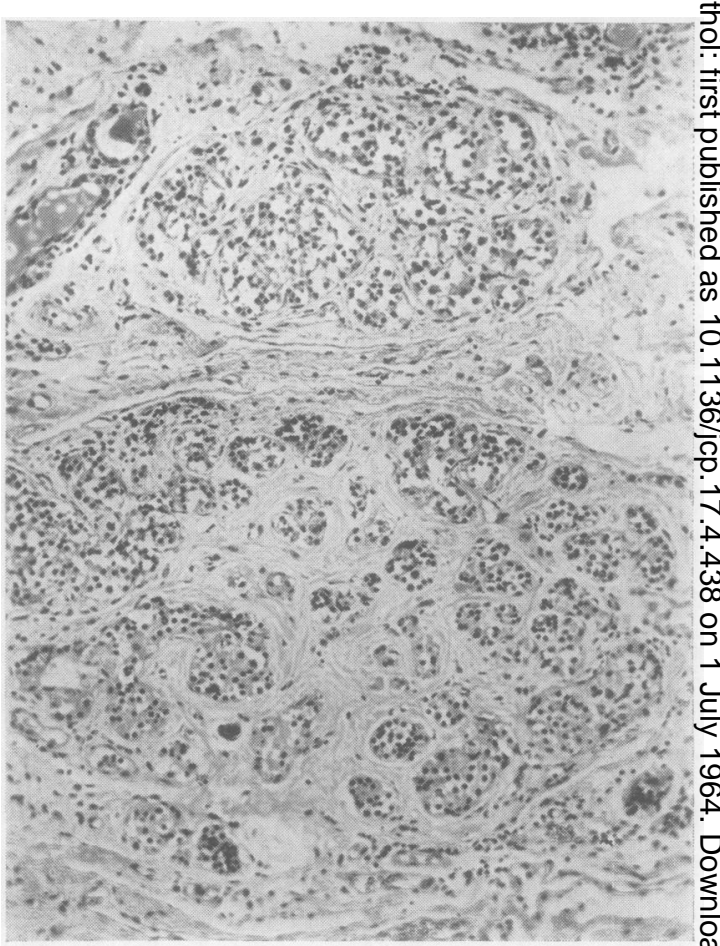

FIG. 5. Case 2. Encapsulated groups of similar cells in the left lobe. Haematoxylin and eosin $\times 100$.

remarkable localized abnormality of epithelial arrange ment, contrasting sharply with the normal acini in the्. intervening tissue (Fig. 7). The epithelial cells in these areas form very small, distorted acini or irregular masses? without colloid secretion. These cells have large pleomorphic nuclei and deep-staining cytoplasm; they resemble oxyphilic epithelium in some respects but theiro arrangement is much more irregular than is ordinarily seen in foci of oxyphilic epithelium. Although cytoo logically similar to the adenocarcinoma, none of these foci show evidence of stromal or lymphatic invasion. In the left lobe is a tiny encapsulated nodule composed of hyaline connective tissue; in a focus of haemorrhage within this nodule is a small group of epithelial cells (Fig. 8) which again resemble the tumour cells.

In all three cases routine sectioning and microscopyo of all other organs which might possibly have beeno the site of a primary carcinoma showed no evidence of such a growth. In none of the cases were pulmon? ary lymphatics invaded by secondary tumouro deposits.

\section{DISCUSSION}

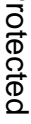

Before considering the relationship of the hypo thyroid state to the development of thyroid carcin 8 oma, one must first be satisfied that these tumour? 


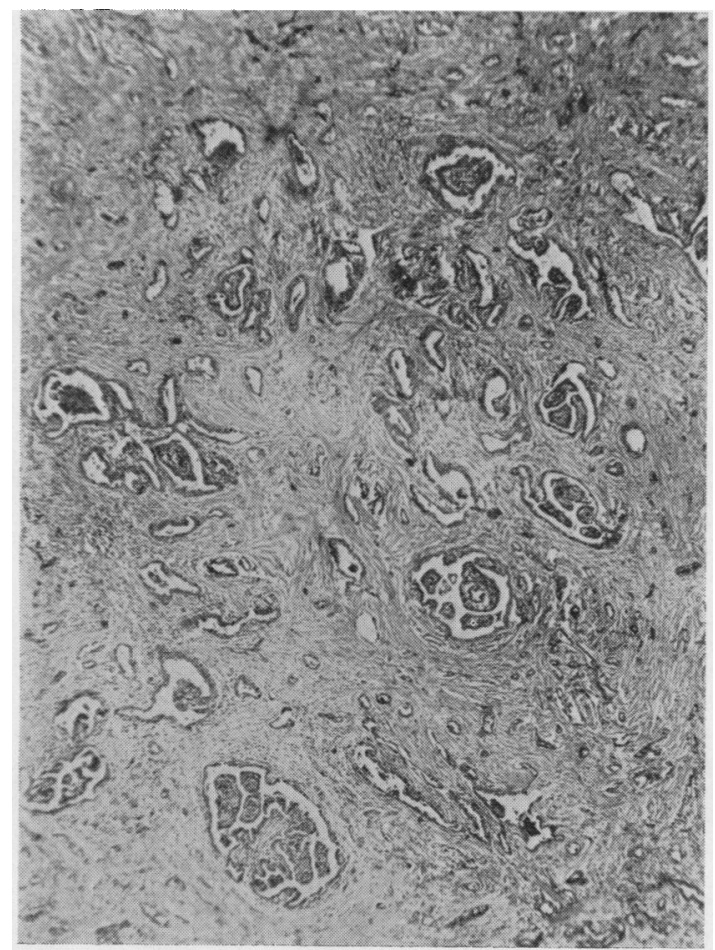

FIG. 6

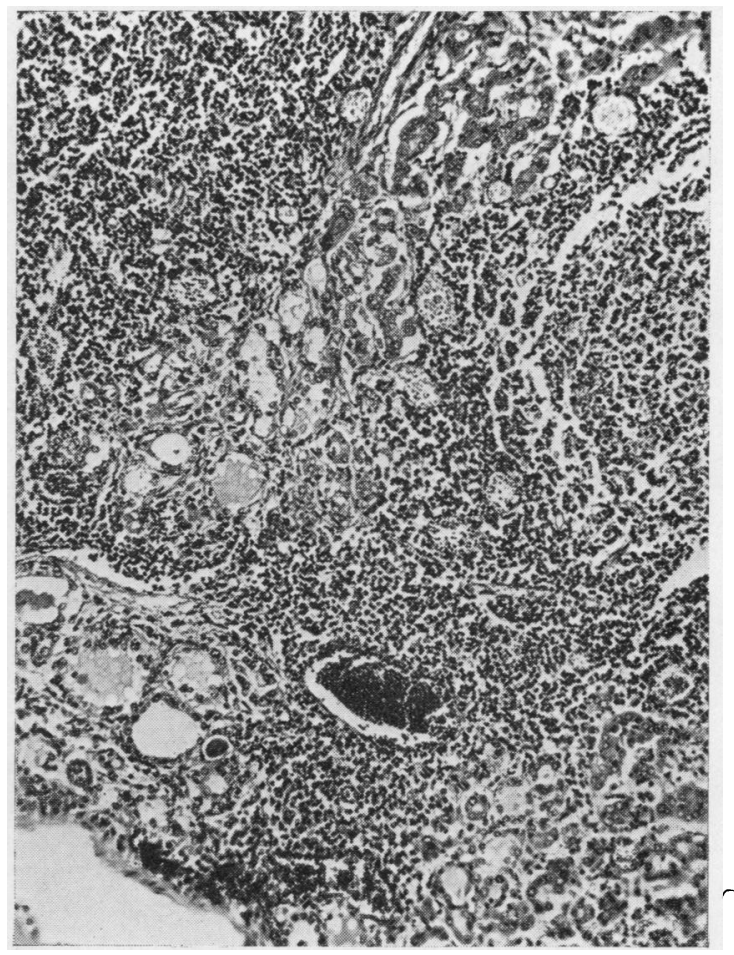

FIG. 7

FIG. 6. Case 3. Papillary adenocarcinoma in the right lobe. Haematoxylin and eosin $\times 30$.

FIG. 7. Case 3. Small irregular acini (top right), between two lymphoid follicles, provide a sharp contrast with normal colloid-containing acini (bottom left). Haematoxylin and eosin $\times 100$.

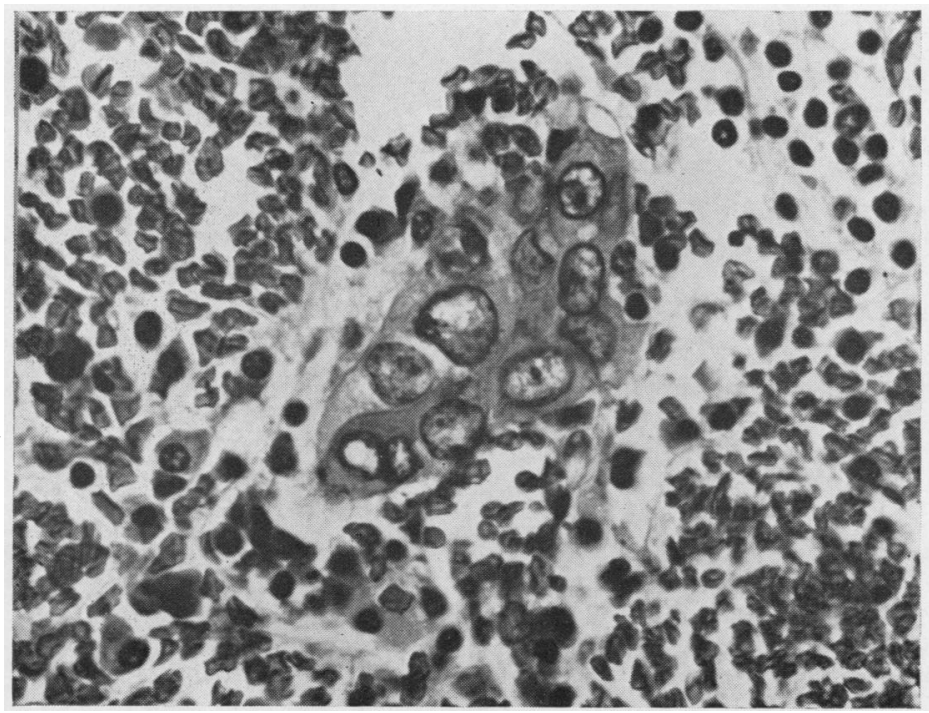

FIG. 8. Case 3. A group of abnormal epithelial cells, surrounded by red cells and lymphocytes, in the centre of a hyaline nodule in the left lobe. Haematoxylin and eosin $\times 650$.

FIG. 8 
are indeed primary, since metastatic carcinoma is about ten times commoner than primary carcinoma in the thyroid (Shimaoka, Sokal, and Pickren, 1962). The failure to find any other site of malignant neoplasm, and the characteristic papillary structure of the tumour in cases 1 and 3, are good evidence of primary carcinoma. Further confirmation is provided by the presence in all three cases of foci which appear to represent transitional stages between non-neoplastic and malignant thyroid epithelium.

The widespread nature of the epithelial change, in contrast to the more usual picture of a solitary carcinoma in a gland which is otherwise substantially normal, may be of significance with regard to the pathogenesis of the condition. In his discussion on malignant change in chronic thyroiditis, Lindsay (1960) also noted transitions between the proliferating epithelium of Hashimoto's disease and frank infiltrating carcinoma, remarking that some portions of the proliferating epithelium midway between the two extremes could not be classified as either benign or malignant with certainty. Studying thyroid carcinoma in the hamster, Fortner, George, and Sternberg (1960) noted that spontaneous cancer occurred in a histologically normal gland, while in experimentally-induced cancer the neoplastic changes were diffuse, suggesting stimulation by thyrotropic hormone.

Experimentally all the conditions leading to the development of thyroid tumours in animals have in common a persistent stimulus to the thyroid via thyrotropic hormone (Thomas, 1958). Iodinedeficient diets, antithyroid drugs, and partial destruction of the thyroid by radioactive iodine have all been used to suppress the production of thyroid hormone and indirectly provoke excessive secretion of thyrotropic hormone. Prolonged administration of propylthiouracil to the rat, for example, will increase blood thyrotropic hormone levels by 70 to $300 \%$ (D'Angelo, 1961). More directly, HaranGhera, Pullar, and Furth (1960) have induced thyroid carcinoma in mice by grafting thyrotropichormone-secreting tumours.

On the basis of experimental evidence, therefore, it might be expected that long-standing hypothyroidism would carry an increased risk of malignant change in the thyroid. With reference to Hashimoto's disease, the past decade has brought increasing evidence for such a relationship. An unduly high incidence of carcinoma in cases of Hashimoto's disease has been reported by Dailey, Lindsay, and Skahen (1955), Piercy (1956), Pollock and Sprong (1958), Woolner, McConahey, and Beahrs (1959), Ryvarden (1960), Shands (1960), Schlicke, Hill, and Schultz (1960), Fowler, Majarakis and Cole (1961) and Chesky, Hellwig, and Welch $\underline{\underline{0}}$ (1962). In some of these studies, such as that of Pollock and Sprong, little care has been taken to $\stackrel{\vec{P}}{\vec{P}}$ distinguish between malignant change in true $\overline{0}$ Hashimoto's disease and the mere association of $\frac{}{0}$ focal chronic inflammatory changes with carcinoma $\frac{\bar{s}}{\vec{D}}$ of the thyroid, so that the likelihood of carcinoma $\stackrel{\mathbb{\Omega}}{\Omega}$ supervening on Hashimoto's disease may have been overestimated. Nevertheless, Lindsay (1960), among others, does make the distinction clear and leaves no. doubt that carcinoma is found more often in the $\vec{\omega}$ presence of diffuse chronic thyroiditis than in glands showing other thyroid disorders.

It would be reasonable to suppose that myx- $\vec{v}$ oedema, which is now widely accepted as a late ${ }_{A}^{*}$ stage of diffuse chronic thyroiditis, would carry at least as great a risk of malignant change. The effect $\infty$ of substitution therapy in suppressing excessive? secretion of thyrotropic hormone has little import- ance in this connexion, since clinically-recognizable $\subseteq$ myxoedema is probably preceded by a long spell of $<$ failing thyroid function and thus of unopposed hypersecretion of thyrotropic hormone.

The occurrence of three examples of carcinoma in 37 cases of myxoedema can give no indication of the true incidence of malignant change. Since two of the three tumours were chance findings, not detected macroscopically but found microscopically in an $\bar{\varnothing}$ initial study of three random blocks of thyroid, it may well be that a more detailed study, subjecting the entire organ to histological examination, would have revealed a higher incidence of carcinoma.

The multinodular condition of the gland in case 1 could be regarded as itself a predisposing factor to malignancy; on this is it not possible to reach any certain conclusion. The incidence of carcinoma in non-toxic nodular goitre is a highly controversial 0 subject, recently reviewed by Meyer (1962). Esti- $₹$ mates have varied widely, but neither Doniach $\frac{9}{5}$ (1960) nor Lindsay (1960) consider benign nodules $D$ to be an important source of carcinoma.

If there is indeed an increased liability to thyroid N carcinoma in myxoedema, some explanation is required for the absence of previous reports of this $\tilde{D}$ nature. With regard to chronic thyroiditis, it is $\mathrm{w}^{\mathrm{O}}$ evident that the risk of carcinomatous change is, from the clinical point of view, negligible, providede the patient is adequately treated with dessicated $\overparen{D}$ thyroid (Crile and Hazard, 1962). The recent reports? arise from an increasingly careful study of surgically excised thyroids, revealing small tumours, the용 majority of which are of low-grade malignancy and $\stackrel{\mathbb{D}}{\mathbb{D}}$ do not constitute a serious threat to the patient's $\stackrel{\mathbb{Q}}{\varrho}$ life. Similarly it may be true that in myxoedema the thyroid occasionally harbours a small carcinoma which, because of its slow rate of growth in ano 
elderly patient, does not manifest itself clinically before death ensues from some other cause.

We thank Professor A. C. P. Campbell for criticism of the manuscript and Mr. N. Mowat and Miss J. Perry for the photomicrographs.

\section{REFERENCES}

Chesky, V. E., Hellwig, C. A., and Welch, J. W. (1962). Amer. Surgn, $28,678$.

Crile, G. Jr., and Hazard, J. B. (1962). Surg. Gynec. Obstet., 115, 101 Dailey, M. E., Lindsay, S., and Skahen, R. (1955). Arch. Surg., 70, 291. D'Angelo, S. A. (1961). Endocrinology, 69, 834.

Doniach, I. (1960). In Recent Advances in Pathology, 7th ed., edited by C. V. Harrison, p. 255. Churchill, London.
Fortner, J. G., George, Phyllis A., and Sternberg, S. S. (1960). Endocrinology, 66, 364.

Fowler, E. F., Majarakis, J. D., and Cole, W. H. (1961). Arch. Surg., $82,925$.

Haran-Ghera, N., Pullar, P., and Furth, J. (1960). Endocrinology, 66, 694.

Lindsay, S. (1960). Carcinoma of the Thyroid Gland, pp. 19-20. Thomas, Springfield, Illinois.

Meyer, P. C. (1962). Brit. J. Cancer., 16, 16.

Piercy, J. E. (1956). Proc. roy. Soc. Med., 49, 174

Pollock, W. F., and Sprong, D. H. (1958). West. J. Surg., 66, 17.

Ryvarden, G. (1960). Zentralb. allg. Path. path. Anat., 101, 475.

Schlicke, C. P., Hill, J. E., and Schultz, G. F. (1960). Surg. Gynec. Obstet., 111, 552.

Sclare, G. (1963). J. Path. Bact., 85, 263.

Shands, W. C. (1960). Ann. Surg., 151, 675.

Shimaoka, K., Sokal, J. E., and Pickren, J. W. (1962). Cancer, 15, 557.

Thomas, C. G., Jr. (1958). Amer. Surg., 24, 728.

Woolner, L. B., McConahey, W. M., and Beahrs, O. H. (1959). J. clin. Endocr., 19, 53 